\title{
A systemic approach to the research of personnel in agriculture of the region
}

\author{
Elena A. Chulkova ${ }^{1, *}$ and Lyaysana I. Rakhmatullina ${ }^{2}$ \\ ${ }^{1}$ Security Corporation LLC, Yekaterinburg, 620109, Russia \\ ${ }^{2}$ Orenburg State Agrarian University, Orenburg, 460014, Russia
}

\begin{abstract}
Development of an innovative economy gives rise to the need to form a highly competent workforce capable of creating and implementing innovations in a short time. This also applies to agriculture as a sector of the economy that ensures the food security of the regions and the country as a whole. The level and quality of the labor force is considered as the most important resource in the activities and development of the agro-industrial complex. A methodical approach to a systematic study of the use of staffing in agriculture in the region is proposed, the difference of which is the use of econometric modeling to assess the impact on the target indicator of the components of staff by areas of activity and level of qualifications. The application of the approach is shown on the example of the sector of agricultural organizations of municipal districts of the Orenburg region.
\end{abstract}

\section{Introduction}

Modern agribusiness meets a growing demand for proficient employees with analytical skills and experience in new and advanced technologies and equipment [1, 2]. Over the last few years, RF agribusiness has seen import reduction and simultaneously, the growth of agricultural stock and foodstuffs export [3]. According to the Decree of the President of the Russian Federation No 204 dated 05.07.2018 the national priorities for further agribusiness development are as follows:

- to create within agribusiness an export-oriented sector based on high-performance manufacturing technologies;

- to man this sector with highly skilled staff able to introduce not only up-to-date technologies, but futuristic technologies as well [4].

Within this context, human capital becomes an essential precondition for competitive growth of regional agrifood systems [5, 6]. A number of measures have been proposed for the reproduction of human capital [7]. Researchers state employees' skill level when specifying engines of growth for agribusiness efficiency. However, these fundamental factors have traditionally been analyzed using predominantly qualitative methods.

All this provides a background for new methodological approaches to study regional agribusiness staffing, its present state, availability and engagement. Moreover, large-scale business operational environment and its sustainability are a basis of economic security of every nation $[8,9]$. Thus, system approach to the research of regional agricultural organizations staffing becomes a top priority.

\section{Methods}

We consider regional agribusiness staffing as a system where agribusiness employees of regional municipal districts function as its elements. We have been studying staff of all agriculture enterprises (irrespective of their business structure and form of business) located within rural districts of the region. For the research, we used official data published in statistics digests and statistical reports of regional Departments of Agriculture.

Agrarian production in the region is a diversified sector of the economy and its result indicator comprises output of diverse business segments, this target indicator being represented by agricultural produce in current costs. According to the statistical reports, agribusiness staff consists of executive staff, professional staff members and workers of mass professions.

To study how stuffing system components influence the target indicator we broke down personnel according to the following agriculture segments:

- crop farming,

- stock breeding,

- agriproduct processing,

- maintenance in business units of agricultural enterprises.

\footnotetext{
Corresponding author: sun244@mail.ru
} 
We further subdivided these components into groups according to employees' qualification levels, which largely depend on the type of their professional fieldspecific education.

For quantitative assessment of the process variables in the staffing system we applied statistical methods:

- structural-dynamic analysis, which helps reveal regional peculiarities and tendencies in staffing;

- regression analysis which enables to discover correlations between a number of factors and target indicators and to get quantitative assessment of the strength of their relationship.

Regression analysis also allowed us to compare the impact of the factors on certain target indicator. When modeling, we applied multiple linear regression.

Assessment of staffing system phenomena and process variables as well as early detection of negative and positive situations within the system serves to improving efficiency of agribusiness as a whole, which has always been regarded as the objective of strategic importance.

\section{Results}

Our methodological approach enabled us to perform systematic research on supply of agribusiness staff and to assess staffing in the agricultural enterprises of all types of business structure and all forms of business located in the municipal districts of Orenburg region. Since rural population of the region makes up $39.4 \%$ (as of 01.01.2020), it is included with the agricultural regions of the country. This is the highest percentage among the 14 regions of the Volga Federal district.

Orenburg region comprises 29 municipal districts, which are home to rural population. Agribusiness is the core activity of the rural districts. Federal Law No 131FZ dated October 6, 2003 set particular tasks for the municipal rural districts to create favorable conditions for agribusiness development within settlements as well as for the development of market system to sell agricultural output.

Municipal districts of the region differ considerably By the volumes of agricultural output in current costs $(W)$ (Table 1).

Table 1. Grouping districts according to the output volume in agricultural enterprises in 2019

\begin{tabular}{|c|c|c|}
\hline & $\begin{array}{c}W, \\
\text { million RUR }\end{array}$ & Municipal districts \\
\hline 1 & More than 1000 & $\begin{array}{c}\text { Sakmara district, Orenburg district, } \\
\text { Tashla district, Oktyabrsky district, } \\
\text { Saraktash district, Buzuluk district, } \\
\text { Adamovka district, } \\
\text { Novosergiyevsky district, } \\
\text { Asekeyevsky district, } \\
\text { Pervomaysky district } \\
\end{array}$ \\
\hline 2 & $\begin{array}{l}\text { From } 500 \text { to } \\
1000\end{array}$ & $\begin{array}{c}\text { Kurmanayevka district, } \\
\text { Sharlyk district, } \\
\text { Kvarkensky district, } \\
\text { Ilek district, Perevolotsk district, } \\
\text { Grachevka district, Severny district, } \\
\text { Buguruslan district, Tulgan district, }\end{array}$ \\
\hline
\end{tabular}

\begin{tabular}{|c|c|c|}
\hline & & $\begin{array}{c}\text { Aleksandrovka district, } \\
\text { Matveyevka district }\end{array}$ \\
\hline 3 & Less than 500 & $\begin{array}{c}\text { Krasnogvardeysky district, } \\
\text { Belyayevka district, } \\
\text { Akbulak district, Novoorsk district, } \\
\text { Totsky district, Svetlinsky district, } \\
\text { Dombarovka district, } \\
\text { Ponomarevka district }\end{array}$ \\
\hline
\end{tabular}

The districts have been ranked by target indicator in descending order and divided into 3 groups according to the target indicator value (more than 1000 million RUR; ranging from 500 to 1000 million RUR; less than 500 million RUR). Among 10 districts of the first group Sakmara district tops the list (5941 million RUR), with Pervomaysky district occupying the bottom line (1028 million RUR). Within the second group (11 districts; items 11-21) fluctuation $W$ of the target indicator ranges from 507.3 (Matveyevka district) to 906.4 million RUR (Kurmanayevka district). Within the third group (8 districts; items 22-29) $W$ varies from 90.8 (Ponomarevka district) to 465.3 million RUR (Krasnogvardeysky district).

Over the last few years, agricultural enterprises of municipal regions have been primarily focused on stockbreeding. That is why we ranged districts in Table 2 according to decrease in the output volume within this type of agricultural activity $\left(W_{1}\right)$. The first group includes 6 districts. Tashla district has the highest target indicator (1647.2 million RUR), while Orenburg district occupies the bottom line (1040.7 million RUR). The second group includes items from 7 to 19, comprising 13 territories. Here target indicator $\mathrm{W} 1$ varies from 553.4 million RUR (Aleksandrovka district) to 960 million RUR (Pervomaysky district). The third group includes 8 territories; $W_{1}$ varies from 78.9 million RUR (Ponomarevka district) to 465.2 million RUR (Matveyevka district). These are items 20-29.

Table 2. Grouping districts according to the volume of stock breeding output in agricultural enterprises in 2019

\begin{tabular}{|c|c|c|}
\hline & $\begin{array}{c}W 1 \\
\text { million } \\
\text { RUR }\end{array}$ & Municipal districts \\
\hline 1 & $\begin{array}{c}\text { More than } \\
1000\end{array}$ & $\begin{array}{l}\text { Tashla district, Oktyabrsky district, } \\
\text { Buzuluk district, Adamovka district, } \\
\text { Saraktash district, Orenburg district }\end{array}$ \\
\hline 2 & $\begin{array}{c}\text { From } 500 \\
\text { to } 1000\end{array}$ & $\begin{array}{c}\text { Pervomaysky district, } \\
\text { Asekeyevsky district, } \\
\text { Novosergiyevsky district, } \\
\text { Kurmanayevka district, } \\
\text { Kvarkensky district, } \\
\text { Sakmara district, Sharlyk district, } \\
\text { Ilek district, Buguruslan district, } \\
\text { Grachevka district, } \\
\text { Perevolotsk district, Tulgan district, } \\
\text { Aleksandrovka district }\end{array}$ \\
\hline 3 & $\begin{array}{c}\text { Less than } \\
500\end{array}$ & $\begin{array}{c}\text { Matveyevka district, } \\
\text { Severny district, } \\
\text { Krasnogvardeysky district, } \\
\text { Belyayevka district, } \\
\text { Novoorsk district, Totsky district, } \\
\text { Akbulak district, Svetlinsky district, }\end{array}$ \\
\hline
\end{tabular}




\begin{tabular}{|l|l|l|}
\hline & & $\begin{array}{l}\text { Dombarovka district, } \\
\text { Ponomarevka district }\end{array}$ \\
\hline
\end{tabular}

While comparing grouping pattern of the districts we found out that distribution of districts within groups mostly coincides, while the items differ. According to stock breeding output grouping we highlighted the districts that shifted from the first group into the second group and from the second into the third group (with respect to grouping according to $W$ ) in italics.

Agribusiness manpower supply in the municipal rural districts in the 21st century has been negatively influenced by restricted reproduction of the rural population, decrease of the proportion of able-bodied persons and growth of the proportion of (re)employed pensioners within the staff age composition and some other factors. Lack of jobs, low wages, substandard social infrastructure contribute to further decline in the birth rates, considerable outward migration flow and demographic burden on the working population [3, 10, 11 and other]. Staff turnover mostly affects workers of mass professions and specialists in comparison to other staff categories.

Development and transformation of the potential staffing in the rural areas depend on demographic processes, particular features of this or that region and agribusiness geographic location. As far as agro-industry is concerned, it is first greatly influenced by climaterelated risks of the area [12]. Orenburg region is potentially drought-prone, which often results in crop failure over a considerable part of the region territory. Thus, in 2010 drought encompassed two thirds of farming lands of the region.

The proportion breakdown of the number of workers in mass professions according to the type of fieldspecific education is presented in Table 3.

Table 3. Proportional breakdown of the number of workers in mass professions by type of field-specific education, $\%$

\begin{tabular}{|l|c|c|c|}
\hline \multicolumn{1}{|c|}{$\begin{array}{c}\text { Field-specific } \\
\text { education }\end{array}$} & $\mathbf{2 0 1 7}$ & $\mathbf{2 0 1 8}$ & $\mathbf{2 0 1 9}$ \\
\hline Higher education & 4.51 & 4.23 & 4.25 \\
\hline $\begin{array}{l}\text { Secondary } \\
\text { special education }\end{array}$ & 31.55 & 30.20 & 35.23 \\
\hline Basic education & 30.54 & 32.06 & 32.09 \\
\hline Training courses & 18.15 & 17.33 & 13.95 \\
\hline $\begin{array}{l}\text { Without professional } \\
\text { education }\end{array}$ & 15.26 & 16.18 & 14.48 \\
\hline
\end{tabular}

Table 4 shows the proportion breakdown of the number of the specialists according to their qualifications, determined by the type of their fieldspecific education.

Table 4. Proportional breakdown of the number of specialists by the type of their field-specific education $\%$

\begin{tabular}{|c|c|c|c|}
\hline $\begin{array}{c}\text { Field-specific } \\
\text { education }\end{array}$ & $\mathbf{2 0 1 7}$ & $\mathbf{2 0 1 8}$ & $\mathbf{2 0 1 9}$ \\
\hline Higher education & 36.02 & 39.34 & 43.17 \\
\hline
\end{tabular}

\begin{tabular}{|c|c|c|c|}
\hline $\begin{array}{c}\text { Secondary special } \\
\text { education }\end{array}$ & 52.92 & 51.77 & 45.90 \\
\hline $\begin{array}{c}\text { Without professional } \\
\text { education }\end{array}$ & 11.04 & 8.89 & 10.97 \\
\hline
\end{tabular}

The total number of agribusiness staff in municipal rural districts is constantly declining. Over the last two years, it dropped from 18.53 to 14.5 thousand people, i.e. by 4.03 thousand people $(21.76 \%)$. Over this period, the total number of specialists (excluding chief specialists) also dropped from 1812 to 1486 people (by $18 \%$ ).

When modeling inner processes within manpower supply system and performing assessment of their impact on the target indicator we have distinguished three stages. At the first stage, we analyzed importance of the agricultural enterprise core activity and revealed their priorities. At the second stage, we performed regression analysis to assess the strength of the relationship between target indicator and the number of workers of mass professions (according to the area of activity and taking into consideration the level of their field-specific education). We assessed the impact of every group of the staff on the agricultural output volume. At the third stage, we assessed performance of the specialists.

Below there is a model showing correlation of the agricultural output of the region and the number of the workers of mass professions according to their business activity:

$$
\begin{gathered}
W=368106- \\
285 u_{1}+2506 u_{2}+9201 u_{3}+2591 u_{4},
\end{gathered}
$$

where $W$ is an annual agricultural output in current prices (thousands RUR);

$u_{1}-u_{4}$ are the number of workers according to their business activity, respectively: crop farming, stockbreeding, agriproduct processing and agribusiness maintenance in business units of agricultural enterprises (persons);

$R$ is a multiple correlation coefficient;

$R^{2}$ is a coefficient of determination.

Model statistical characteristics are as follows: $R=0.8448 ; R^{2}=0.7137$;

$\beta$-coefficients: $-0.0403 ; 0.2654 ; 0.5244 ; 0.2663$.

Model analysis (1) shows that fluctuation of the independent variables (the number of workers according to their business activity) account for the essential part of the process under study. According to the coefficient of determination the share of fluctuation $W$ in this case is $71.37 \%$. Multiple correlation coefficient value indicates a high strength of linear relationship between the model factors and target indicator.

All regression equation variables are significant. While variable $u_{1}$ is inversely associated with $W$, other factors are associated with it directly. Consequently, the increase of the number of the staff engaged in crop farming by one person, with other variable remaining unchanged, will decrease $W$ by 285 thousand RUR. When fulfilling similar terms for each of the factors $u_{2}$ $u_{4}$ there is an increase of outcome value by 2506, 9201 and 2591 thousand RUR respectively. Standard model 
representation enables comparative study of the factors $u_{1}-u_{4}$ according to their impact on the target indicator $W$ based on the estimated values of $\beta$-coefficients. In the model (1) $\beta$ - coefficient of the factor $u_{3}$ has the maximum value. That is why the number of stuff in the agriproduct processing in business units of agricultural enterprises has the greatest impact on the target indicator.

The value of the direct correlation $W$ with the number of stuff in the agriproduct processing is almost two times as strong as that in stockbreeding and maintenance. It is also by 13.01 times as big as the inverse relationship $W$ with the factor $u_{1}$. However it is worth mentioning that total number of the staff engaged in agriproduct processing makes up only $3.81 \%$ of the workers of mass professions total number.

The greater part of the agribusiness staff is engaged in crop farming (47.84 \%), a little more than one forth in stock breeding $(26.58 \%)$, almost one fifth - in agribusiness maintenance within business units of agricultural enterprises $(21.76 \%)$.

We chose stockbreeding to exemplify the strength of the target indicator correlation with the number of workers taking into account their level of field-specific education. Here are the designations:

$W_{1} \quad$ is stockbreeding output in current prices (thousands RUR);

$u_{2 A}, u_{2 B}, u_{2 C}, u_{2 D}$ are the number of personnel engaged in stock breeding in groups with higher, secondary special, basic education and training courses, respectively;

$u_{2 E}$ is the number of the group comprising workers without professional education.

In the groups $u_{2 B}, u_{2 C}, u_{2 D}$ we took into consideration only agribusiness field-specific education, while in the group $u_{2 A}-$ any higher education.

Regression equation for the correlation of the agricultural output and the number of its staff members according to their qualification is as follows:

$$
\begin{gathered}
W_{1}=359639+15705 u_{2 A}+1445 u_{2 B}+1258 u_{2} C+ \\
+3726 u_{2 D}+5693 u_{2 E}
\end{gathered}
$$

Model statistical characteristics are:

$R=0.711 ; R 2=0.5055$;

$\beta$-coefficients: $0.14 ; 0.2506 ; 0.1245 ; 0.098 ; 0.4705$.

The explained share of the variation in $\mathrm{W} 1$ due to the variation of the factors of the stock breeding workers in the model (2) is quite high. It makes up $50.55 \%$. All coefficients of the independent variables have positive signs, i.e. their growth leads to the $W_{1}$ increase. Here the value of the $W_{1}$ increase depends on the employee's education level. Within the group with higher education increase of $u_{2 A}$ factor by one person, with other variables remaining unchanged, leads to the $W_{1}$ increase at average by 15705 thousand RUR. Likewise, within the group of personnel with secondary special education increase of $u_{2 B}$ factor by one person will boost $W_{1}$ by 1445 thousand RUR, etc. It should be noted that in this model the impact of $u_{2 A}$ factor is the strongest. However, the number of personnel with higher education is not large.
Comparing $\beta$-coefficients we can see that workers of mass professions have the greatest impact on $W_{1}$ $(21.59 \%)$. Then come staff members (in descending order) with secondary special education, with higher education, basic education and training courses. Their share in work force supply of the stockbreeding is 40.53, $1.43,30.7$ and $5.76 \%$ respectively.

Then we studied impact of the field-specific education of the agribusiness specialists (excluding chief specialists) on the target indicator $W$. Below is the model showing correlation strength of the output volume and the number of the specialists according to their qualification:

$$
W=-204597+38515 k_{A}+28109 k_{B}-
$$

$38753 k c$,

where $k_{\mathrm{A}}, k_{\mathrm{B}}, k_{\mathrm{C}}$ stand for the number of specialists in the groups with higher education, secondary special education and without professional education.

Model statistical characteristics are as follows: $R=0.7895 ; R^{2}=0.6233$;

$\beta$-coefficients: $0.6312 ; 0.4691 ;-0.4285$.

Three independent variables in this model account for $62.33 \%$ of $W$ fluctuation. Coefficients of the factors $k_{A}$ and $k_{B}$ have positive values, so the specialists with field-specific education have positive impact on target indicator $W$. Increase of these factors by one unit of measure results in growth of the target indicator in regional agribusiness enterprises, taken cumulatively, at average by 38515 and 28109 thousand RUR, respectively.

It should be pointed out that according to $\beta$ coefficients $k_{A}$ impact on $W$ is 1.35 times as strong in comparison to $k_{B}$ factor. Specialists without adequate education (their $k_{C}$ coefficient having negative sign) have negative impact on $W$. Noteworthy, $k_{\mathrm{C}}$ impact on $W$ is almost equal to that of $k_{B}$. $\beta$-coefficient correlation with variables $k_{C}$ and $k_{B}$ makes up 0.91. Increase of the number of workers of mass professions by one person, with other variables of the model (3) remaining unchanged, will considerably decrease $W$ (by 38753 units of measure).

Negative value of the free term in regression equations is a frequent phenomenon, and is typically accounted for by the requirement to provide a certain level of factors for production activities, i.e. actual production activity is impossible under zero value of resources.

We verified relevancy of the multiple regression models (1)-(3) applying Fisher's criterion, which proved their adequacy and significance of the results received.

Thus, output volumes in the agri-industry of the region are greatly influenced by the type of agribusiness as well as by field-specific education of the staff members, which specifies their qualification.

\section{Discussion}

Negative value of $u_{1}$ in the analytical dependence of the 
region agricultural annual production volume on the number of workers indicates a problematic situation in the crop farming. In comparison to other sectors of the regional agribusiness, crop farming remains far from being prosperous and under current conditions its development seems cost prohibitive. Agriproduct processing has a major positive impact on fluctuation $W$ and a potential growth of this target indicator; however, the share of personnel engaged in this business is comparatively low. Consequently, to enhance the $W$ result it is recommended to expand agriproduct processing involving extra work force and retraining employees to develop their competency within specific area if need be.

Stock breeding equation lacks factors that correlate with the target indicator $W_{1}$ negatively. It is possible to enhance $W_{1}$ increasing the number of people in the group - by one person with higher professional education it is the increase by 15705 thousand RUR and by a group of workers of mass professions it is by 5693 thousand RUR. Their correlation makes up 2.26 times. However, it is the number of workers of mass professions that has the strongest impact on $W_{1}$ since their share in the total number of the engaged personnel is 15.1 times as big as that of the $u_{2 A}$ factor. Actually, $u_{2 A}$ factor comes only third by its impact on $W_{1}$ indicator. $\beta$-coefficients correlation of these factors is 3.36, that is total impact of $u_{2 A}$ is weaker than that of $u_{2 E}$. Consequently, the level of field-specific education in agribusiness is as important as the work experience. Under conditions of high turnover, personnel with basic and course education have a smaller impact on the effective indicator $W_{1}$ and it is necessary to increase the level of their knowledge and skills by organizing additional training.

Modeling revealed another problematic situation, which occurs when agribusiness enterprises employ people without adequate education to occupy the positions of specialists. The impact this category of staff may have on performance is rather strong and agribusinesses should take measures to reduce staff turnover as well as measures to improve staff competency, which might be possible to do by getting the second education. Thanks to modern educational technologies, one can get education almost in any field through extramural form of study.

Advance of digital economy provides accumulation of large data stores, which provides managers with opportunity to perform multi-aspect research on the current state and use of personnel in agribusiness at all levels (regional, municipal or within the enterprise). Application of mathematical methods enables a thorough analysis to assess parameters of a variety of processes as well as to timely reveal and monitor problematic situations, both evident and latent.

\section{Conclusion}

The proposed methodical approach to the systemic research of the use and assessment of staffing of agricultural organizations in municipal districts of the region differs from other approaches by representing those employed in this sector of the economy in the form of a single system, which has its own specificity and development trends. In addition, a decomposition of the number of employed by the enlarged types of activity and further by the level of qualifications (by the type of their professional field-specific education) was carried out, which made it possible to perform an in-depth detailed analysis of the internal processes of agricultural production based on econometric modeling.

Approbation of the approach was carried out on the data for the Orenburg region. Going forward we plan to perform regression analysis both of other major types of activities and that of certain branches of crop farming and stockbreeding. This will allow identifying problem situations in staffing, providing information support for the choice of compensatory and preventive measures, as well as carefully substantiating the priorities of personnel policy.

In the future, it is also possible to solve optimization problems for the use of personnel. For example, determining the optimal proportions of the categories of staffing (managers, specialists, or workers) or a comprehensive assessment of the qualitative characteristics of workers, taking into account the variety of their parameters. The study of such complex phenomena as the innovative activity of managers is also relevant. In agricultural production, this applies, first, to primarily top and middle-ranking managers and chief specialists.

\section{References}

1. T.A. Vlasova, Conditions for the formation and assessment of the state of human resources in the agricultural sector of the economy, Reg. Econ.: Theory and Pract., 12, 107 (2016)

2. Yu.N. Shumakov, M.P. Tushkanov, Labor resources of the village: state and prospects, Econ. of agricult. of Russ., 7, 74 (2015)

3. L.V. Bondarenko, The programme-oriented approach to rural development, AIC: econ., manag., 2, 47 (2020)

4. Strategic directions and priorities of regional development in the context of global challenges (Ural Branch of the Russian Academy of Sciences, Yekaterinburg, 2019)

5. V.P. Neganova, Yu.F. Chistiakov, V.V. Drokin, A.S. Zhuravlev, V.M. Sedelnikov, Competitiveness of regional agri-food systems. Theoretical overview, Econ. of reg., 1, 329 (2021)

6. A.S. Klychova, S.F. Girfanov, G. D. Krupin, I.N. Safiullin, Increasing competitiveness in conditions of corporate governance of enterprises of the agro-industrial complex of the Republic of Tatarstan, Bull. of Kazan State Agrar. Univ., 4, 110 (2017)

7. N.V. Vorobeva, N.N. Mineeva, Human capital as a factor in the development of the agrarian sector of an industrially developed region, Reg. Econ., 4, 75 (2008) 
8. L. Zingales, Towards a Political Theory of the Firm, J. of Econ. Perspect., 31, 113 (2017)

9. I. Demchenko, O. Baltic, The Problem of Unprofitable Activity of Enterprises in Ukraine, J. of Econ. Stud., 2, 64 (2018)

10. T.D. Degtyareva, E.A. Chulkova, L.I. Rakhmatullina, M.M. Mursalimov, Reproduction and use of labor resources in the agro-industrial complex of the region, URFU Bull. Ser. Econ. and Manag., 4, 642 (2015)
11. E.V. Mikhalkina, N.A. Kosolapova, O.Ya. Senkiv, Model for assessing the impact of factors of socioeconomic development of Russian regions on the formation of human potential, Terra Econ., 2, 57 (2015)

12. E.A. Chulkova, L.I. Rakhmatullina, Formation and rational use of labor resources in agriculture (LLC IPK “University”, Orenburg, 2017) 